\title{
A IMPORTÂNCIA DO MARKETING PARA AS MICROS E PEQUENAS EMPRESAS
}

\section{ARTIGO ORIGINAL}

OLIVEIRA, Vinícius Cardoso de ${ }^{1}$

DENDASCK, Carla Viana ${ }^{2}$

OLIVEIRA, Vinícius Cardoso de. A importância do Marketing para as Micros e Pequenas Empresas. Revista Científica Multidisciplinar Núcleo do Conhecimento. Ano 05, Ed. 02, Vol. 02, pp. 28-40. Fevereiro de 2020. ISSN: 2448-0959, Link de acesso: https://www.nucleodoconhecimento.com.br/marketing/micros-e-pequenasempresas

\section{RESUMO}

De acordo com o Sebrae, em 2018, as micro e pequenas empresas eram responsáveis por $52 \%$ das posições de emprego, e, correspondem $99 \%$ das empresas existentes no Brasil. No entanto, mesmo com esta representatividade $58 \%$ destas empresas conseguem ultrapassar os cinco anos de existência. Estima-se que esse alto percentual de mortalidade das organizações esteja relacionado a falta de planejamento e de adoção aos princípios básicos da administração. Desta feita, esse artigo tem como objetivo realizar uma reflexão, utilizando-se da metodologia de revisão bibliográfica, sobre a importância do marketing para estas organizações, bem como, a necessidade de os empreendedores adotarem uma postura estratégica

${ }^{1}$ Pós-Graduação em Comunicação Pública - Faculdade Venda Nova do Imigrante. Pós-Graduação em MBA em Marketing Executivo - Faculdade Venda Nova do Imigrante. Pós-Graduação em MBA em Gestão de Equipes e Lideranças - Faculdade Venda Nova do Imigrante.

2 Teóloga. Doutora em Psicanálise Clínica. Pesquisadora do Centro de Pesquisa e Estudos Avançados, São Paulo, SP. 
através das possibilidades de marketing, especialmente com relação ao Marketing Digital, garantindo assim a sustentabilidade da organização.

Palavras-Chave: Marketing, empresas, clientes.

\section{INTRODUÇÃO}

As micro e pequenas empresas no Brasil chegam a representar $99 \%$ das organizações, e expressam importantes números para a economia brasileira. De acordo com o Sebrae (2018), estas empresas ainda representam 52\% dos empregos, $39 \%$ das folhas de salários e $27 \%$ do Produto Interno Bruto. No entanto, mesmo com essa representatividade no cenário nacional, o índice de mortalidade destas organizações é um dos maiores do mundo, fazendo com que essas empresas sejam rotativas.

Em nível nacional, estima-se que de cada 100 novas micro e pequenas empresas abertas, $58 \%$ irá fechar nos próximos 5 anos. Esse índice pode variar de acordo com o desenvolvimento regional, bem como, de acordo com a capacidade de gestão de seus respectivos empreendedores (SEBRAE, 2018; 2019).

De acordo com Santos et al. (2005) e Ferreira et al. (2012) grande parte do insucesso das micro e pequenas empresas está associado ao perfil do empreendedor, que muitas vezes acabam por negligenciar os processos administrativos e, consequentemente a falta de adoção estratégica de ações, como por exemplo, as ações de marketing.

Desta feita, esse artigo está estruturado de forma a apresentar breves elucidações capazes de trazer embasamento para reflexões a cerca do marketing e suas contribuições para as micro e pequenas empresas no Brasil. 


\section{O MARKETING}

O marketing que em português quer dizer mercadologia, nasceu com o crescimento industrial e com o aparecimento de grandes empresas. Se desenvolveu através da necessidade de uma nova forma de administração, trazendo grandes transformações entre o mercado dos vendedores para o mercado dos compradores.

Roesch (1996, p.44) enfatiza que:

$\mathrm{Na}$ área do marketing, concentra-se análises competitivas, do mercado ou comportamento dos consumidores, onde inclui um perfil e análise dos consumidores, definindo os segmentos do mercado, elaborando plano de marketing, onde são utilizados pelas organizações, com decisões nas relações do preço, do produto, da distribuição e da comunicação, bem como a administração de vendas.

Ao observarmos a palavra "Marketing" de uma forma pragmática, notamos que o termo tende a assumir uma tradução da sua forma, ou seja, é possível considerar que o Marketing consiste em um estudo mercadológico, sendo este, uma ferramenta destinada ao meio administrativo no qual possibilita uma observação das tendências e criação de novas oportunidades para o consumo, proporcionando a satisfação dos clientes e atendendo as expectativas financeiras e mercadológicas das empresas de prestação de serviços ou de produção.

O marketing também pode ser definido como um processo de planejamento e execução, que se desenvolve a partir da sua concepção, orçamentação, promoção e distribuição de ideias de produtos e serviços para criar trocas satisfatórias sobre objetivos individuais e organizacionais. (COBRA, 2010). É uma atividade realizada a médio e longo prazo com o único objetivo de assegurar a fidelidade dos clientes, aplicando conhecimentos avançados de mercado e a sondagem de opiniões, bem como uma pesquisa direta com o público, intuindo estabelecer um contato direto com as necessidades dos mesmos. 
Geralmente, o marketing é notado como uma tarefa para criar, para promover, além de fornecer os bens e serviços aos clientes, quer sejam pessoas físicas e jurídicas. Os profissionais do marketing tendem a se envolver no mesmo os bens, os serviços, organizações, informações, as experiências, os eventos, lugares, pessoas, propriedades, e as ideias (KOTLER, 2000, p. 25).

Busca-se maximizar a satisfação do consumidor, suas escolhas e qualidade de vida. Esta é uma área de atuação muito ampla, onde envolve uma série de atividades como o processo de criação, planejamento e desenvolvimento de produtos ou serviços, a fim de atender as necessidades do consumidor na hora da compra.

Para Kotler (2006, p.4)

Pode ser considerado que haverá a necessidade de se vender. Mas o Marketing possui o objetivo de tornar mais supérfluo os esforços de venda do produto. A finalidade do Marketing é o de conhecer e de entender o seu cliente, a ponto de que o produto ou serviço seja mais adequado e passe a vender sozinho. Assim, o Marketing deve resultar num cliente disposto para comprar, onde deve tornar um produto e serviço disponível.

Através do marketing é possível atender todas as necessidades de consumo, não se limitando somente aos bens consumíveis, mas promovendo ideias e direcionando programas, dando origem ao processo de desenvolvimento do mercado competitivo.

Atualmente, essa é uma área que valoriza a construção de um relacionamento satisfatório a longo prazo entre empresa e cliente, fazendo com que ambas partes sejam beneficiadas com a parceria. Não se trata apenas da propagação do valor do produto aos seus usuários, ou efetividade na comercialização. É também o compromisso com a busca constante de melhorias para a qualidade de vida dos consumidores. (COBRA, 1992). 
Podemos considerar o Marketing uma via dupla, que liga organização e mercado. $O$ mercado consegue entender quais são os problemas do público alvo através das informações coletadas por meio de pesquisas realizadas. A organização fornece ao mercado produtos e serviços, que são direcionados aos desejos e necessidades de seus consumidores, resultando em recursos financeiros e clientes satisfeitos.

Foi introduzido o conceito que diz que todas as empresas devem ser orientadas para atender seus clientes e ao próprio mercado. Muitas empresas vendem produtos e serviços em intermédio de grande variedade através de canais diretos e indiretos. As propagandas em massa deixaram de ser tão eficientes. Hoje, as organizações exploram novas formas para se relacionarem, como por exemplo o entretenimento através do marketing em redes sociais. Os consumidores se expressam cada vez mais, informando as empresas sobre quais produtos e serviços os agradam, a forma como desejam adquiri-los, e quando desejam isso. (KOTLER e KELLER, 2012).

O marketing tende a se tornar um processo social e gerenciável através da criação, propagação de valores e possibilidades de troca, fazendo com que grupos sociais consigam obter o que necessitam e desejam, é formado então, uma imagem positiva deste processo. (KOTLER, 1996). Por meio do marketing é possível entender as maiores necessidades das empresas, promovendo a elas soluções, através de produtos e ideias. Tudo é pensado e implementado com base no que aquele órgão precisa no momento, ou seja, através de uma estratégia, são executadas medidas positivas de curto e longo prazo.

Para Campomar e Ikeda (2006), produto, promoção, praça/pontos de vendas, e preço, são quatro variáveis controláveis do marketing, sendo estas conhecidas pelos quatro P's do marketing, ou o por mix do marketing. Estas variáveis tendem a ser consideradas como controláveis onde cada uma pode vir a ser modificada ou adaptada pelas decisões gerenciais. O composto de marketing é um conjunto de ações numa empresa, com a finalidade de influenciar toda demanda de seu produto. Através do equilíbrio entre estes pilares, se torna possível o sucesso da marca. 


\section{ESTRATÉGIAS DE MARKETING NAS PEQUENAS E MICRO - EMPRESAS}

A importância de haver estratégias de Marketing nas pequenas empresas, faz com que as mesmas passem a se adequar e melhorar continuamente seu processo de trabalho, mantendo firmemente sua marca no mercado, montando estratégias sólidas, formando excelentes e competentes profissionais, motivadores e conscientes do sucesso da empresa.

Pouco se sabe sobre efeitos das técnicas do marketing que são aplicadas nas MPEs, mesmo elas estado presentes na literatura, onde os resultados de uma aplicação informal de estratégias do marketing nas MPEs, ainda pouco são estudados e principalmente pelas dificuldades do acesso às empresas (SOLÉ, 2013).

O marketing dentro das pequenas e micro empresas deve realizar um processo de planejar e executar os planos estabelecidos do preço, promoção e distribuição das ideias, dos produtos e dos serviços ofertados, havendo uma entrega da satisfação aos clientes de forma individual. As estratégias do Marketing visam alcançar os objetivos da pequena empresa, considerando o ambiente atuante e o impacto dessas relações diante do bem-estar na sociedade.

Apesar de sua grande importância, as pequenas empresas, ainda caminha em passos lentos, no sentido em conhecer, em analisar e em propor alternativas para o segmento do marketing. Supostamente, algumas das razões para que ocorra a falta de investimento nesta área é a importância econômico-social das pequenas empresas e as dificuldades em o empresário em mudar o foco de suas vendas, sendo responsáveis pelo elevado número de fechamento das mesmas (SANTOS; ALVES; ALMEIDA, 2005, p. 60).

Diante da competição acirrada que as micro e pequenas empresas atravessam, considerando o atendimento como um elo importantíssimo da corrente de 
relacionamento com o cliente, percebe-se que o sucesso das mesmas está ligado diretamente ao marketing, no entanto, é necessário um conhecimento profundo sobre o assunto para gerenciar e coordenar uma tomada de decisão, fazendo assim, com que o consumidor confie na oferta do produto oferecido, sendo fiel e evitando a perda dos mesmos.

Através de análise é possível se verificar quanto ao grau de satisfação dos consumidores em relação a um produto e os motivos de preferência pelos concorrentes, passando a identificar desta maneira, o potencial mercadológico dos produtos ou dos serviços, se estão sendo praticados de maneira otimizada com relação às vendas (COBRA, 2000, p.43).

Conquistar o cliente num mercado competitivo como o atual, necessita de um aprofundamento maior, com pesquisas sobre o comportamento, expectativas e necessidades do consumidor, sendo assim, as estratégias de marketing numa empresa, podem conduzir as empresas de pequeno porte, a manter-se no mercado globalizado.

O marketing nas pequenas e micros empresas (MPE), tende a ser informal e simples e isso ocorre diretamente no tamanho das empresas, por sua informalidade e pela forte influência dos empreendedores nas suas decisões (JONES; ROWLEY, 2011).

As estratégias de marketing nas pequenas empresas, englobam as atividades que são referentes às relações da troca, sendo orientadas em satisfazer os desejos, assim como as necessidades de seus consumidores, e desta forma, faz com que os mesmos se fidelizem, fazendo assim com que estas empresas consigam uma colocação no mercado competitivo.

O marketing implementado pelas MPEs, passa a ser diferente do que é utilizado por grandes empresas, sendo ele o marketing tradicional, onde trata-se de exercício gerencial que é aprendido durante suas experiências no cotidiano (SOLÉ, 2013). 
Estar antenado as estratégias que o Marketing oferece para as pequenas e micro empresa é reconhecer que não se consegue ter evolução no mercado, sem que pelo menos um setor esteja atraído pelos planos que ele oferece, sendo assim, o marketing está presente no sucesso das empresas de todos os portes.

O marketing nas pequenas empresas, também tende a ser um processo social, onde através da criação, das ofertas e de trocas dos produtos de maior valor, com outros indivíduos e grupos, obtendo o que se necessitam ou desejam, fazendo assim com que tanto a empresa quanto o consumidor saiam beneficiados.

As vendas estão voltadas às necessidades dos vendedores e o marketing, está voltada para as necessidades dos compradores. Venda em si, preocupa-se na necessidade do vendedor converter o seu produto em forma de dinheiro, já o marketing satisfaz as necessidades de um cliente em meio de produtos e todo conjunto de coisas nas quais são associadas em sua criação e na entrega ao consumo final (KOTLER e KELLER, 2012, p.14).

A tarefa mais importante da pequena empresa, para o marketing é determinar as necessidades e os desejos de seus consumidores, procurando adaptar-se, usando de formas variadas para proporcionar a satisfação desses desejos, uma vez que neste contato ocorre uma troca entre empresa e consumidor.

\section{MARKETING DE RELACIONAMENTO NAS PEQUENAS EMPRESAS}

Para conquistar clientes, além de aumentar o número das vendas em um estabelecimento, é fundamental que as pequenas empresas tracem objetivos, os quais se tornam fundamentais para o sucesso da mesma e para isso, existem diversas formas de atrair este público, onde deve-se buscar contemplar todos os acessos de divulgação. 
A concepção do marketing de relacionamento é que as empresas estão para o mercado, sobre o novo posicionamento dinâmico, diálogo com o cliente e pesquisa qualitativa (BOGMANN, 2000).

A cada dia, a concorrência tende a estar cada vez mais acirrada, fazendo com que as empresas de pequeno porte, passem a perder clientes para as grandes empresas, mas o ideal é que seja elaborada estratégias para divulgar seus produtos e serviços, permitindo que o consumidor esteja sempre envolvido na qualidade da oferta, assim, é possível um contato direto com o mesmo, usando métodos nos quais se tornem benéficas tanto para empresa quanto para o cliente.

Kotler (2000) ressalta que o marketing de relacionamento tende a representar importante mudança dos paradigmas, por tratar-se da evolução de mentalidade competitiva conflituosa em uma abordagem na qual esteja pautada por uma interdependência cooperacional.

Conforme o marketing avança pelo século XXI, uma mudança significativa também vem acontecendo, na maneira como empresas interagem com os consumidores. $O$ relacionamento do marketing para as pequenas empresas é muito viável e pode trazer ótimas oportunidades para o negócio, desta forma, cabe que o empreendedor passe a conhecer as possibilidades e seu cliente, para que escolha as estratégias adequadas ao perfil de seu consumidor.

A visão de forma tradicional do marketing como processo simples de troca, ou o marketing orientado na transação, vem sendo substituída por uma abordagem diferenciada, de prazo mais longo, que enfatiza construir relacionamentos com um consumidor por vez (BOONE e KURTZ, 2009).

O marketing de relacionamento, proporcionam este contato direto com o cliente, seja através do uso da tecnologia ou contato direto, onde utiliza-se de estratégias que façam despertar no mesmo, a vontade de divulgar a marca do estabelecimento, pela qualidade dos produtos e pelo serviço prestado de forma personalizada, desta maneira, as pequenas empresas passam a ganhar seu espaço no mercado.

Disponível em: https://www.nucleodoconhecimento.com.br/marketing/micros-e-pequenas- 
Estratégias de marketing tracionais focavam em atrair consumidores e fechar acordos. Os profissionais de marketing de hoje percebem que, apesar de ser importante atrair novos consumidores, é ainda mais importante estabelecer e manter relacionamento com eles para que se tornem consumidores leais (BOONE e KURTZ, 2009, p. 28).

Como mencionam os autores, o marketing tinha a finalidade de atrair clientes e promover a venda de seus produtos e serviços para as empresas, com o passar dos tempos, o marketing foi sendo aprimorado e passou também a manter um relacionamento com esse cliente, com a finalidade de mantê-los fieis e ao mesmo tempo atrair novos clientes.

Esse conceito tem de se expandir para incluir fornecedores e funcionários também. A longo prazo, esse relacionamento pode ser traduzido em valor para o cliente (BOONE e KURTZ, 2009).

O Marketing de relacionamento, pode ser definido como sendo uma estratégia, na qual possui o objetivo de criar e de manter um relacionamento mais próximo entre clientes e empresa, utilizando-se de métodos capazes de estreitar as formas de atendimento.

Além disso, o marketing de relacionamento, torna-se essencial para o desenvolvimento de lideranças no mercado, além da rápida aceitação dos novos produtos e dos serviços, da consecução de uma fidelidade dos consumidores às marcas ou as empresas (BOGMANN, 2000).

Uma das vantagens do Marketing de Relacionamento é o fato de esta estratégia, tornar os clientes defensores da marca, trazendo assim novos clientes, através Marketing Boca a Boca que é gerado.

Marketing de relacionamento pressupõe uma interatividade, conectividade e criatividade, fazendo com que o cliente possa realmente ser uma parte das estratégias da empresa no planejamento dos produtos 
e dos serviços em um processo de forma dinâmica e contínua (BRAIDO, 2005, p. 99 e 100).

O Marketing de relacionamento, tendem a envolver todas as ações realizadas nas pequenas empresas a fim de manter o seu público fiel, num constante relacionamento, para assim conquistar a fidelidade. Desta forma, para se conquistar os objetivos traçados pela empresa, é necessário uma série de ações, com a finalidade de encantar o cliente, através de inovações, sejam em atendimento personalizado, preço ou produto.

De acordo com Gordon (2001, p.31):

O marketing de relacionamento torna-se um processo contínuo da identificação e da criação dos novos valores com os clientes individuais e compartilhamento dos seus benefícios em sua parceria continua. Isso passa a envolver uma compreensão, concentração e administração da colaboração entre os fornecedores e os clientes nos quais são selecionados para a criação e compartilhamento dos valores mútuos, através da interdependência e do alinhamento organizacional.

Marketing de relacionamento torna-se um conjunto de estratégias, as quais são previamente pensadas para o envolvimento, principalmente, da construção de uma identidade e divulgação da marca. Então, a partir dessas ações, as pequenas empresas buscam como objetivo, prospectar quanto a fidelização do cliente e assim firmar-se diante da concorrência.

Marketing de relacionamento significa conhecer cada cliente individualmente. Essa relação é a estratégia que permite o relacionamento com os clientes de forma individual, conhecendo suas preferencias, costumes, hábitos do consumo e do comportamento. A sua função principal é promover informações que apoiem às gerencias e equipes a atingirem suas metas (LAS CASAS, 2000). 


\section{CONSIDERAÇÕES FINAIS}

Este trabalho procurou enfatizar a importância do marketing para o sucesso das pequenas empresas, onde o atendimento ao cliente é uma estratégia fundamental, proporcionando reflexões em torno do assunto e promovendo conhecimento sobre a qualidade dos produtos e serviços, mantendo os clientes fiéis, sem possibilidade de perdê-los, alcançando assim, a permanência no mercado perante seus concorrentes.

É muito importante que as pequenas e microempresas que pretendem crescer no mercado, construam uma marca forte e trabalhem seu posicionamento, contando com uma identidade visual, permitindo assim, que os seus clientes e consumidores reconheçam de forma fácil os conteúdos e imagens que simbolizam sua empresa.

As pequenas empresas, buscam cada vez mais estratégias que possam favorecer seu crescimento no mercado, investindo e mantendo o compromisso de agradar o seu cliente, seja com produtos inovadores, preços, ou serviços prestados, pois trabalhar o marketing nos tempos atuais é fundamental para que o cliente se sinta mais atraído pela empresa.

É necessário, antes de utilizar estratégias do marketing em favor do crescimento da pequena empresa, que se conheça seu cliente, pois ele é responsável pelos resultados das vendas, além de promover uma imagem positiva e a divulgação boca a boca, sendo esta uma das ferramentas que possui mais importância para promover uma marca.

Para se desenvolver um bom plano de marketing para as pequenas empresas, é importante saber quais as expectativas e as demandas de seus clientes, o que se espera com o produto ou serviço e as características valorizadas por eles. Desta forma, é fundamental que seja definido as melhores formas de estratégias para uma abordagem, que garanta uma mensagem relevante e de forma adequada, mantendo um bom relacionamento com os mesmos através de sua marca. 
Torna-se essencial que as pequenas empresas e seus clientes, tenham bons relacionamentos, focalizando um atendimento de qualidade, evitando assim, a insatisfação, conseguindo identificar quais são as suas necessidades e mantendo uma relação duradoura.

Sendo assim, as estratégias de marketing nas pequenas empresas são essenciais para que estas consigam fornecer aos seus clientes uma imagem positiva, seja no atendimento, seja no comprometimento através de seus produtos. Contudo é necessário conhecer o seu cliente e saber exatamente como fazer a sua propaganda, sua abordagem, enfim, a melhor forma de conseguir atender as necessidades dos mesmos e manter-se firme no mercado.

A realização desta pesquisa, confirmam-se as inúmeras teorias que o marketing traz para a pequena empresa, sendo ele, o principal diferencial em atrair clientes, visto que através de boas estratégias é que se consegue alcançar todos os objetivos traçados, além de manter as perspectivas e a concorrência no mercado competitivo.

Quando se fala de marketing, percebe-se ainda, que o marketing digital pode ser encarado como um grande diferencial para as micro e pequenas empresas, pois dentro do ambiente virtual estas podem equiparar o seu potencial competitivo ao das grandes organizações.

\section{REFERÊNCIAS}

BOGMANN, Itzhak Meir. Marketing de relacionamento: estratégias de fidelização e suas implicações financeiras. Nobel, 2000.

BOONE, Louis E.; KURTZ, David L. Marketing contemporâneo. Cengage Learning, 2009.

BRAIDO, Quelen E. Marketing de relacionamento: oportunidade para desenvolvimento e crescimento contínuo no setor financeiro. Revista Eletrônica de Contabilidade. Rio Grande do Sul. v.1, n.3, mar-mai 2005. 
CAMPOMAR, Marcos Cortez; IKEDA, Ana Akemi. O Planejamento de Marketing e a Confecção de Planos: Dos Conceitos a um Novo Modelo. São Paulo: Editora Saraiva, 2006.

COBRA, Marcos. Administração de marketing. 2. ed. São Paulo: Atlas, 1992.

COBRA, Marcos. Marketing de serviço financeiro. São Paulo: Cobra, 2000.

COBRA, Marcos. Administração de Marketing: São Paulo: Atlas, 2010.

FERREIRA, Luis Fernando Filardi et. al. Análise quantitativa sobre a mortalidade precoce de micro e pequenas empresas da cidade de São Paulo. Gest. Prod., São Carlos, v. 19, n. 4, p. 811-823, 2012

GORDON, lan. Marketing de relacionamento. Estratégias, Técnicas e Tecnologias para conquistar clientes e mantê-los para sempre. São Paulo Ed. Futura, 2001.

JONES, R.; ROWLEY, J. Entrepreneurial marketing in small businesses: a conceptual exploration. International Small Business Journal, v. 29, n. 1, p. 25-36, 2011.

KOTLER, Philip. Administração de Marketing: análise, planejamento, implementação e controle. 4ํㅗㄹ. ed. São Paulo: Atlas, 1996.

KOTLER, Philip. Administração de Marketing-10 Edição, $7^{\text {a }}$ reimpressãoTradução Bazán Tecnologia e Lingüística; revisão técnica Arão Sapiro. 2000.

KOTLER, Philip. Administração de Marketing / Philip Kotler. Kevin Lane Keller; tradução Monica Rosenberg, Brasil Ramos Fernandes, Claudia Freire; revisão técnica Dilson Gabriel dos Santos. - 12 ed - São Paulo: Pearson Prentice Hall, 2006.

KOTLER, Philip; KELLER, Kevin Lane. Administração de marketing: A Bíblica do Marketing. 2012.

LAS CASAS, Alexandre Luzzi. Administração de marketing: conceitos, planejamento e aplicações à realidade brasileira. Editora Atlas SA, 2000.

Disponível em: https://www.nucleodoconhecimento.com.br/marketing/micros-e-pequenas- 
ROESCH, Sylvia Maria Azevedo. Projetos de estágio e de pesquisa do curso de administração: guias para estágios, projetos e estágios e trabalho de conclusão de curso. São Paulo: Atlas, 1996.

SEBRAE. Panorama dos pequenos negócios. Encontrado em: https://www.sebrae.com.br/Sebrae/Portal\%20Sebrae/UFs/SP/Pesquisas/Panorama dos_Pequenos_Negocios_2018_AF.pdf, 2018

SANTOS, Leonardo L. S.; ALVES, Ricardo C.; ALMEIDA, Kenneth N. T. Formação de estratégia nas micro e pequenas empresas: um estudo no centro-oeste mineiro. 2005. Disponível em: http://www.scielo.br/scielo.php?script=sci_arttext\&pid=S003475902007000100006. Acesso em: 22 de jan. 2020.

SOLÉ, M. Entrepreneurial marketing: conceptual exploration and link to performance. Journal of Research in Marketing and Entrepreneurship, v. 15, n. 1, p. 23-38, 2013.

Enviado: Agosto, 2019.

Aprovado: Fevereiro, 2020. 